\title{
BMJ Open Magnitude and associated factors of suicidal ideation and attempt among people with epilepsy attending outpatient treatment at primary public hospitals in northwest Ethiopia: a multicentre cross-sectional study
}

\author{
Kabtamu Nigussie, ${ }^{1}$ Bizuneh Tesfaye, ${ }^{2}$ Alemu Lemma, ${ }^{2}$ Habtamu Kerebih (D) ${ }^{2}$
}

To cite: Nigussie K, Tesfaye B, Lemma A, et al. Magnitude and associated factors of suicidal ideation and attempt among people with epilepsy attending outpatient treatment at primary public hospitals in northwest Ethiopia: a multicentre crosssectional study. BMJ Open 2021;11:e043227. doi:10.1136/ bmjopen-2020-043227

- Prepublication history is published online only. To view please visit the journal online (http://dx.doi.org/10.1136/ bmjopen-2020-043227)

Received 29 July 2020 Revised 09 December 2020 Accepted 19 December 2020

Check for updates

(c) Author(s) (or their employer(s)) 2021. Re-use permitted under CC BY-NC. No commercial re-use. See rights and permissions. Published by BMJ.

${ }^{1}$ Department of Psychiatry, School of Nursing and Midwifery, College of Health and Medical Sciences, Haramaya University, Harar, Ethiopia ${ }^{2}$ Department of Psychiatry, School of Medicine, College of Medicine and Health Sciences, University of Gondar, Gondar, Ethiopia

Correspondence to Habtamu Kerebih; habtishk@gmail.com

\section{ABSTRACT}

Objective This study aimed to assess magnitude and associated factors of suicidal ideation and attempt among people with epilepsy attending outpatient treatment at primary public hospitals, northwest Ethiopia using suicide module of World Mental Health Survey initiative version of the WHO, composite international diagnostic interview. Design Multicentre-based cross-sectional study was used.

Setting Data were collected using face to face interview from patients with epilepsy who attended outpatient treatment at primary public hospitals at northwest Ethiopia.

Participants Adult patients with epilepsy $(n=563)$ who came to attend outpatient treatment during the study period were included in the study using systematic random sampling technique.

Outcome measures Suicidal ideation, suicidal attempt and factors associated with suicidal ideation and attempt.

Results The overall magnitude of suicidal ideation and attempt was $26.5 \%$ and $12.6 \%$, respectively. Being woman adjusted $\mathrm{OR}((\mathrm{AOR})=1.68,95 \% \mathrm{Cl} 1.09$ to 3.23$)$, living alone ( $\mathrm{AOR}=2.4,95 \% \mathrm{Cl} 1.47$ to 3.92), divorced/widowed/ ( $A O R=2.2,95 \% \mathrm{Cl} 1.09$ to 7.8 ), family history of suicidal attempt (AOR=2.53, 95\% $\mathrm{Cl} 1.34$ to 4.79), depression ( $\mathrm{AOR}=3.18,95 \% \mathrm{Cl} 1.85$ to 5.45$)$, anxiety ( $\mathrm{AOR}=2.92$, $95 \% \mathrm{Cl} 1.68$ to 5.09 ), comorbid medical illness ( $\mathrm{AOR}=2.60$, $95 \% \mathrm{Cl} 1.17$ to 5.82 ) and poor social support (AOR=2.35, $95 \% \mathrm{Cl} 1.26$ to 4.40 ) were statistically associated with suicidal ideation. Depression ( $\mathrm{AOR}=4.87,95 \% \mathrm{Cl} 2.56$ to 9.28) living alone ( $\mathrm{AOR}=2.66,95 \% \mathrm{Cl} 1.62$ to 5.41 ), family history of committed suicide (AOR=2.80, 95\% Cl 1.24 to 6.39), taking medication for mental illness ( $A O R=2.17$, $95 \% \mathrm{Cl} 1.06$ to 4.46), hazardous alcohol use ( $\mathrm{AOR}=2.10$, $95 \% \mathrm{Cl} 1.05$ to 4.23 ) were statistically associated with suicidal attempts at a $p$ value $<0.05$.

Conclusion This study showed that the magnitude of suicidal ideation and attempt was high among people with epilepsy. Being woman, living alone, having depression and anxiety, single, divorced/widowed in marital status, family history of suicidal attempt and poor social support were statistically associated with suicidal ideation. Having
Strengths and limitations of this study

- This is a multicentre study to assess the magnitude of suicidal ideation and suicidal attempt among patients with epilepsy attending treatment at primary healthcare settings.

- The study identified various factors associated with both suicidal ideation and suicidal attempt.

- Study used standardised tools to assess both suicidal ideation, suicidal attempt and independent variables with both patient interview (primary data) and chart review (secondary data).

- Recall bias could be a limitation to this study particularly for questions related to an outcome variable suicidal ideation.

- Since the data were collected during a time when there was fear of COVID-19 pandemic, patients with epilepsy particularly with other chronic physical comorbid condition were thought to send their relatives to collect their monthly medications and this might have an effect on the current results.

depression, living alone, family history of suicide attempt, hazardous alcohol use and drug taking for mental illness were statistically associated with suicidal attempt. Based on the findings of this study early screening, detection and management of suicide were recommended in people with epilepsy.

\section{BACKGROUND}

Suicide is fatal act that represents the person's wish to die. There is complex process that involves a series of pathways and mechanisms that starts from initiation of suicidal ideation to planning for days, weeks or even years before acting, while others take their lives seemingly on impulse without premeditation. ${ }^{2}$ The Diagnostic and Statistical Manual of Mental Disorders defines suicidal ideation as a thinking about, considering or making 
plans for suicide and suicidal attempt a deliberate, selfdestructive act with a clear expectation of death that is non-fatal. ${ }^{3}$

The burden of suicide constitutes a serious public health issue in the world. ${ }^{4}$ According to a global estimate from the WHO, around 800000 people die due to suicide annually. This is corresponding to an age-standardised suicide rate-of around 11.5 per 100000 people-a figure equivalent to someone dying in every $40 \mathrm{~s} .{ }^{5}$ The worldwide burden of suicide is estimated to increase to $2.4 \%$ by 2020 year, and the rate of death due to suicide will be one person every $20 \mathrm{~s}^{6}$

Suicidal acts result from a complex interaction of biological, psychological, sociological, cultural and environmental factors. ${ }^{7}$ From the biological and psychological conditions, people with mental and neurological illness such as epilepsy are vulnerable. Epilepsy is a chronic disorder of the brain and is one of the most common serious neurological disorders worldwide with no boundary to age, race, social class, nationality or geographical location. ${ }^{8}$ It affects more than 50 million people in the world. ${ }^{9}$ The prevalence of people with epilepsy (PWE) among the general population varies across the countries from $0.5 \%$ to $5 \% .{ }^{10}$ The communitybased epidemiological study in Ethiopia reported that PWE were 5.2/1000 population. ${ }^{11}$ Epilepsy affects relationship with family and friends, employment, school, leisure activities and results in social and economic consequences. Each of these effects may lead to high magnitude of comorbid psychiatric illness among PWE. ${ }^{12}$

PWE are at higher risk for suicide when compared with the general population. For example, the life-time prevalence of suicidal ideation among PWE that was reported $25 \%$ is higher than people without epilepsy $13 \% .{ }^{13}$ The suicidal rate reported that people with temporal lobe epilepsy (TLE) 6\%-25\% times when compared with $1.4 \%-$ $6.9 \%$ in the general population. ${ }^{14}$ This indicated that suicide is common comorbid psychiatric illness among PWE. ${ }^{15}$ Similarly, different study results showed that PWE are high risk for suicidal ideation and attempt. ${ }^{16}{ }^{17}$ The estimated lifetime prevalence of suicidal attempt among PWE ranged from $3.3 \%$ to $14.3 \%,{ }^{18}$ whereas about $38 \%$ of patients with epilepsy had suicidal ideation. ${ }^{17}$ The estimated prevalence of suicidal ideation and attempts was $45.2 \%$ and $28.6 \%$, respectively. ${ }^{19}$ Around $11 \%$ of deaths among PWE are due to suicide and the suicide attempt increase the chance of later completing suicide by $38 \%{ }^{20}$ Results from meta-analysis indicated that the pooled prevalence for suicide ideation (24 studies) and suicide attempts (18 studies) was $23.2 \%$ and $7.4 \%$, respectively. ${ }^{21}$ Centres for disease control and prevention report that the suicide rate among people with epilepsy is $22 \%$ higher than the general population with $16.89 / 100000$ people with epilepsy compare with 13.84/100 000 in the general population. $^{22}$

The greatest risk factors of suicidal ideation and attempts among people with epilepsy is psychiatric disorders including depression and other mental disorders. ${ }^{23}$
Poor social support, drug treatment for mental illness, those who had psychiatric comorbidity such as comorbid depression, low economic status and unemployment were also reported risk factors from prior studies. ${ }^{24}$ Other factors included poor interpersonal relationship, stigma related to the epilepsy and pre-existing psychiatric illness. ${ }^{25-27}$ In addition, early age onset of epilepsy, antiepileptic drug polytherapy, high seizure frequency and duration of epilepsy were factors found to significantly associated with suicidal ideation and attempt. ${ }^{132}$

Despite this burden and consequences, there is limited study done on suicide ideation and attempt among people with epilepsy in eastern Africa as well as in Ethiopia. There was a single study conducted in Addis Ababa Ethiopia in 2014 in Saint Amanuel Specialized Mental Hospital the only specialised mental hospital in Ethiopia that provide. The suicidal ideation and attempt among people with epilepsy reported in the study was $29.8 \%$ and $14.1 \%$, respectively, with various significantly associated risk factors. ${ }^{24}$ However, there are limited data in the country particularly suicide among patients with epilepsy in settings where psychiatry service limited and or not available including in patients attending primary hospitals. Therefore, this study aimed to assess the magnitude and associated factors of suicidal ideation and attempt among people with epilepsy. This would help for future integrated intervention and it would be an input of information for policymakers to institute intervention strategies.

\section{METHODS}

\section{Study design and setting}

Institutional based cross-sectional study was conducted from 15 March to 1 May 2020, at central Gondar zone primary public hospitals in four primary hospitals named, 'Wogera', 'Dembia', 'Delagi' and 'Aykel' primary hospitals, which are located in the northwest part of Ethiopia .

\section{Study participants}

All adult patients (age $\geq 18$ years), who had been clinically diagnosed with epilepsy and who were at outpatient treatment at Delagi, Wogera, Dembia and Aykel primary hospitals were study participants. Patients who were unable to communicate and seriously ill at the time of the data collection were not included.

\section{Patient and public involvement}

No patients were involved.

\section{Sampling}

The adequate number of samples required for this study were 569 , determined by using single population propor-

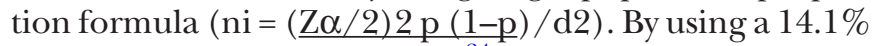
prevalence of suicidal attempt ${ }^{24}$ and setting $3 \%$ tolerable margin of error, $95 \% \mathrm{CI}$ and $10 \%$ non-response rate. A systematic sampling method was used to select study participants from selected hospitals during the study 
period using the number of patients following treatment per month as a sampling frame in each of the hospitals. Study participants were recruited based on proportional allocation from each primary hospital.

\section{Data collection and measurements}

Data were collected by face to face interviews using a structured questionnaire and through patients' chart reviews. Suicidal ideation and attempt were assessed by items that were adopted from module of World Mental Health survey initiative version of the $\mathrm{WHO}$ composites international diagnostic interview in which suicide was studied and validated in Ethiopia both at clinical and community settings with internal consistence Cronbach's alpha $=0.97 .{ }^{29}{ }^{30}$ Its Cronbach's alpha in current study was 0.85 . Standardised and validated measurements in low-income countries including Ethiopia were used to assess other variables including Fast alcohol assesment tool (FAST) for hazardous alcohol use, ${ }^{31}{ }^{32}$ Hospital Anxiety and Depression Scale for depression and anxiety ${ }^{33} 34$ and Kilifi stigma scale (KSS) for perceived stigma. ${ }^{35}$ Social support was collected by Oslo-3 item of Social Support Scale. It is 3-item questionnaires commonly used to assess social support and it had been used in several studies. The sum of score scale was ranging from 3 to 14 , which had three categories: poor support 3-8, moderate support 9-11 and strong support $12-14{ }^{34}$ The internal consistence, Cronbach's alpha of Olso-3 items in the current study was 0.81. Eight trained Bachelors of Science in psychiatric nurses collected the data using the Amharic version questionnaires.

\section{Data processing and analysis}

The data were checked for completeness and consistency and entered to Epi-Data V.4.6.0.2 and was exported to SPSS V.20 for analysis. The binary logistic regression model was used. Bivariate and multivariate logistic regression analysis was performed to identify associated factors to outcome variables. All variables with a $p$ value less than 0.20 at bivariate analysis were entered into the multivariate logistic regression model. A $p$ value of $<0.05$ was considered statistically significant, and the adjusted OR with $95 \%$ CI was calculated. Goodness of model fitness was checked by using Hosmer-Lemeshow test.

\section{RESULTS}

Sociodemographic characteristics of respondents from a total of 569 samples, 563 participants were included in the study with response rate of $98.9 \%$. The median age of respondents was 29 and IQR was 23-36 years. The majority of them $57.5 \%$ (324) was men. Regarding living arrangement of participants, $63.7 \%$ (359) were living with family, the majority of participants $65.2 \%$ (367) was orthodox by religion and $33.7 \%$ (190) was farmers as shown below in table 1 .

\section{Clinical, psychosocial and substance-related factors of respondents}

Majority, (68.2\% (384)), of participants reported the age onset of epilepsy when they were 18 years and above.
Table 1 Sociodemographic characteristics of people with epilepsy of central Gondar zone primary public hospitals, northwest, Ethiopia, $2020(n=563)$

\begin{tabular}{|c|c|c|c|}
\hline Variable & Category & $\begin{array}{l}\text { Frequency } \\
(n=563)\end{array}$ & Percentage \\
\hline \multirow[t]{2}{*}{ Sex } & Male & 324 & 57.5 \\
\hline & Female & 239 & 42.5 \\
\hline \multirow[t]{5}{*}{ Age } & $18-24$ & 169 & 30.0 \\
\hline & $25-31$ & 197 & 35.0 \\
\hline & $32-38$ & 85 & 15.1 \\
\hline & $39-45$ & 58 & 10.3 \\
\hline & $>45$ & 54 & 9.6 \\
\hline \multirow[t]{3}{*}{ Marital status } & Single & 208 & 36.9 \\
\hline & Married & 283 & 50.3 \\
\hline & $\begin{array}{l}\text { Divorced/ } \\
\text { widowed }\end{array}$ & 72 & 12.8 \\
\hline \multirow{2}{*}{$\begin{array}{l}\text { Living } \\
\text { arrangement }\end{array}$} & With family & 359 & 63.8 \\
\hline & Alone & 204 & 36.2 \\
\hline \multirow[t]{3}{*}{ Religion } & Orthodox & 363 & 64.5 \\
\hline & Muslim & 128 & 22.7 \\
\hline & $\begin{array}{l}\text { Protestant/ } \\
\text { catholic }\end{array}$ & 72 & 12.8 \\
\hline \multirow[t]{6}{*}{ Occupation } & $\begin{array}{l}\text { Government } \\
\text { worker }\end{array}$ & 55 & 9.8 \\
\hline & Merchant & 120 & 21.3 \\
\hline & Framer & 190 & 33.7 \\
\hline & Student & 62 & 11.0 \\
\hline & Unemployed & 82 & 14.6 \\
\hline & Household worker & 54 & 9.6 \\
\hline \multirow[t]{4}{*}{ Education } & $\begin{array}{l}\text { No formal } \\
\text { education }\end{array}$ & 119 & 21.1 \\
\hline & $\begin{array}{l}\text { Primary } \\
\text { school(1-8) }\end{array}$ & 242 & 43.0 \\
\hline & $\begin{array}{l}\text { Secondary } \\
\text { school(9-12) }\end{array}$ & 137 & 24.3 \\
\hline & $\begin{array}{l}\text { Diploma and } \\
\text { above }\end{array}$ & 65 & 11.5 \\
\hline \multirow[t]{2}{*}{ Residence } & Rural & 350 & 62.2 \\
\hline & Urban & 213 & 37.8 \\
\hline
\end{tabular}

Nearly half, $(44.0 \%$ (248)), of the respondents had 1-6year duration of treatment while $59.9 \%$ (337) had up to 5 -year duration of illness. More than three-forth, $79.6 \%$ (448), of participants were taking one antiepileptic medication. Out of the total study participants, $21.1 \%$ (119) and 29.8\% (168), were found to have anxiety and depression. respectively. whereas $8.75 \%{ }^{36}$ had comorbid medical illness. Family history of suicide indicated that about $12.4 \%$ (70) had family history of suicide attempt and $7.3 \%^{37}$ had family history of committed suicide. Regarding social support, $42.6 \%$ (240) had moderate social support. Out of the total participant. 66.4\% (374) 
Table 2 Description of clinical, psychosocial, substance use characteristics of people with epilepsy of central Gondar zone primary public hospitals, northwest, Ethiopia, 2020

\begin{tabular}{|c|c|c|c|}
\hline Variable & Category & $\begin{array}{l}\text { Frequency } \\
(n=563)\end{array}$ & Percentage \\
\hline \multirow{2}{*}{$\begin{array}{l}\text { Age onset of } \\
\text { epilepsy }\end{array}$} & Under 18 & 179 & 31.8 \\
\hline & 18 and above & 384 & 68.2 \\
\hline \multirow{4}{*}{$\begin{array}{l}\text { Duration of } \\
\text { treatment (years) }\end{array}$} & Up to 1 & 163 & 29.0 \\
\hline & $1-6$ & 248 & 44.0 \\
\hline & $7-12$ & 115 & 20.4 \\
\hline & $>12$ & 37 & 6.6 \\
\hline \multirow{4}{*}{$\begin{array}{l}\text { Duration of illness } \\
\text { (years) }\end{array}$} & Up to 5 & 337 & 59.9 \\
\hline & $6-10$ & 140 & 24.9 \\
\hline & $11-15$ & 67 & 11.9 \\
\hline & 16 and above & 19 & 3.4 \\
\hline \multirow[t]{2}{*}{ Number medication } & One & 448 & 79.6 \\
\hline & Two and above & 115 & 20.4 \\
\hline \multirow[t]{4}{*}{ Types of medication } & Phenobarbital & 322 & 57.2 \\
\hline & Phenytoin & 133 & 23.6 \\
\hline & $\mathrm{Na}$ valproate & 85 & 15.1 \\
\hline & Carbamazepine & 23 & 4.1 \\
\hline \multirow{4}{*}{$\begin{array}{l}\text { Frequency of } \\
\text { seizure }\end{array}$} & Very frequent & 86 & 15.3 \\
\hline & Frequent & 138 & 24.5 \\
\hline & Occasional & 251 & 44.6 \\
\hline & Rare & 88 & 15.6 \\
\hline \multirow[t]{2}{*}{ Depressive } & Yes & 168 & 29.8 \\
\hline & No & 395 & 70.2 \\
\hline \multirow[t]{2}{*}{ Anxiety } & Yes & 119 & 21.1 \\
\hline & No & 444 & 78.9 \\
\hline \multirow{2}{*}{$\begin{array}{l}\text { Comorbid medical } \\
\text { illness }\end{array}$} & Yes & 49 & 8.7 \\
\hline & No & 514 & 91.3 \\
\hline \multirow{2}{*}{$\begin{array}{l}\text { Family history of } \\
\text { suicidal attempt }\end{array}$} & Yes & 70 & 12.4 \\
\hline & No & 493 & 87.6 \\
\hline \multirow{2}{*}{$\begin{array}{l}\text { Family history of } \\
\text { committed suicide }\end{array}$} & Yes & 41 & 7.3 \\
\hline & No & 522 & 92.7 \\
\hline \multirow{2}{*}{$\begin{array}{l}\text { Family history of } \\
\text { mental illness }\end{array}$} & Yes & 57 & 10.1 \\
\hline & No & 506 & 89.9 \\
\hline \multirow{2}{*}{$\begin{array}{l}\text { Family history of } \\
\text { epilepsy }\end{array}$} & Yes & 58 & 10.3 \\
\hline & No & 505 & 89.7 \\
\hline \multirow{2}{*}{$\begin{array}{l}\text { Medication taking } \\
\text { for mental illness }\end{array}$} & Yes & 88 & 15.6 \\
\hline & No & 475 & 84.4 \\
\hline \multirow[t]{3}{*}{ Social support } & Poor & 196 & 34.8 \\
\hline & Moderate & 240 & 42.6 \\
\hline & Strong & 127 & 22.6 \\
\hline \multirow[t]{2}{*}{ Perceived stigma } & Yes & 374 & 66.4 \\
\hline & No & 189 & 33.6 \\
\hline \multirow[t]{2}{*}{ Ever substance use } & Yes & 231 & 41.0 \\
\hline & No & 332 & 59.0 \\
\hline \multirow{2}{*}{$\begin{array}{l}\text { Current substance } \\
\text { use }\end{array}$} & Yes & 156 & 27.7 \\
\hline & No & 407 & 72.3 \\
\hline
\end{tabular}

Continued
Table 2 Continued

\begin{tabular}{llcl}
\hline Variable & Category & $\begin{array}{l}\text { Frequency } \\
(\mathbf{n = 5 6 3 )}\end{array}$ & Percentage \\
\hline Hazardous alcohol & Yes & 78 & 13.9 \\
use & No & 485 & 86.1 \\
\hline
\end{tabular}

had not perceived stigma and 27.7\% (156) of participants were current substance use as shown below in table 2 .

\section{Magnitude of suicidal ideation and attempt among people with epilepsy}

The lifetime magnitude of suicidal ideation and attempt in this study was $26.5 \%$ (149) with (95\% CI 23.1 to 30.4) and $12.6 \%$ (71), with (95\% CI 9.9 to 15.5 ), respectively. Among the respondents who had a suicidal ideation, $59.1 \%$ (88) had suicidal ideation within the last 12 months and $15.8 \%$ (89) had planned to commit suicide in a lifetime (table 3 ).

\section{Factors associated with suicidal ideation among people with epilepsy}

In bivariate logistic regression analysis, variables like being woman, living alone, single, divorced/widowed, family history of suicidal attempt, family history of committed suicide, depression, anxiety, ever substance use, taking medication for mental illness, comorbid medical illness, perceived stigma, hazardous alcohol use and poor social support were significantly associated with suicidal ideation. In multivariate logistic regression analysis, variables like being woman, living alone, family history of a suicidal attempt, anxiety, depression, being single, divorced/widowed, comorbid medical illness and poor social support were statically significant for suicidal ideation with $\mathrm{p}$ value less than 0.05 . To identify the effect of each variable, a multicollinearity statistics test was checked and the variance inflation factors of each variable were a range of 1.03-2.54 (table 4).

\section{Factors associated with suicidal attempt among people with epilepsy}

In bivariate logistic analysis, variables like living alone, being divorce/widowed, family history of committed suicide, family history of mental illness, depression, taking medication for mental illness, comorbid medical illness, perceived stigma and hazardous alcohol use were statically significant to suicidal ideation at $p$ value less than 0.2. In multivariate logistic analysis, variables like living alone, family history of committed suicide, depression, taking medication for mental illness and hazardous alcohol use were statically significant at $p$ value less than 0.05 (table 5).

\section{DISCUSSION}

The current study showed that the lifetime magnitude of suicidal ideation was $26.5 \%$ with (95\% CI 23.1 to 30.4$)$. Regarding magnitude, the finding of current study was 
Table 3 Distribution of suicidal and attempt among of people with epilepsy of central Gondar zone primary public hospitals, northwest, Ethiopia, $2020(n=563)$

\begin{tabular}{|c|c|c|c|}
\hline Variable & Category & $\begin{array}{l}\text { Frequency } \\
(n=563)\end{array}$ & Percentage \\
\hline \multirow{2}{*}{$\begin{array}{l}\text { Ever suicidal } \\
\text { ideation }\end{array}$} & Yes & 149 & 26.5 \\
\hline & No & 414 & 73.5 \\
\hline \multirow{2}{*}{$\begin{array}{l}\text { Duration of } \\
\text { ever suicidal } \\
\text { ideation }\end{array}$} & $\leq 12$ & 88 & 59.1 \\
\hline & $>12$ & 61 & 40.9 \\
\hline \multirow{2}{*}{$\begin{array}{l}\text { Suicidal thought } \\
\text { in last on month }\end{array}$} & Yes & 36 & 6.4 \\
\hline & No & 527 & 93.6 \\
\hline \multirow{2}{*}{$\begin{array}{l}\text { Ever plan of } \\
\text { suicide }\end{array}$} & Yes & 89 & 15.8 \\
\hline & No & 474 & 84.2 \\
\hline \multirow{2}{*}{$\begin{array}{l}\text { Duration of ever } \\
\text { plan }\end{array}$} & $\leq 12$ & 63 & 71.6 \\
\hline & $>12$ & 25 & 28.4 \\
\hline \multirow[t]{2}{*}{ Suicidal attempt } & Yes & 71 & 12.6 \\
\hline & No & 492 & 87.4 \\
\hline \multirow{2}{*}{$\begin{array}{l}\text { Duration of } \\
\text { suicidal attempt }\end{array}$} & $\leq 12$ & 47 & 66.2 \\
\hline & $>12$ & 24 & 33.8 \\
\hline \multirow{2}{*}{$\begin{array}{l}\text { Suicidal attempt } \\
\text { in last } 1 \text { month }\end{array}$} & Yes & 19 & 3.4 \\
\hline & No & 544 & 96.6 \\
\hline \multirow{3}{*}{$\begin{array}{l}\text { Frequency of } \\
\text { suicide attempt }\end{array}$} & Once & 47 & 66.2 \\
\hline & Twice & 19 & 28.8 \\
\hline & More than twice & 5 & 7.0 \\
\hline \multirow{6}{*}{$\begin{array}{l}\text { Reason for } \\
\text { suicidal attempt }\end{array}$} & Family conflict & 13 & 18.3 \\
\hline & Death of family & 17 & 23.9 \\
\hline & Financial loss & 11 & 15.5 \\
\hline & $\begin{array}{l}\text { Related to current } \\
\text { illness }\end{array}$ & 14 & 19.7 \\
\hline & Physical illness & 9 & 12.7 \\
\hline & Others & 7 & 9.9 \\
\hline \multirow{5}{*}{$\begin{array}{l}\text { Methods of } \\
\text { attempt }\end{array}$} & Hanging & 26 & 36.6 \\
\hline & Poisoning & 25 & 35.2 \\
\hline & Sharp tools & 7 & 9.9 \\
\hline & Drug overdose & 10 & 14.1 \\
\hline & $\begin{array}{l}\text { Jumping from } \\
\text { high place }\end{array}$ & 3 & 4.2 \\
\hline
\end{tabular}

in line with study carried out in Brazil, which reported a prevalence of $28.9 \%,{ }^{38}$ a study from Egypt that showed 23.5\% of suicidal ideation ${ }^{39}$ and in Addis Ababa Ethiopia where the prevalence of suicidal ideation was $29.8 \% .{ }^{24} \mathrm{It}$ was also similar with a pooled prevalence result of a metaanalysis that reported $23.2 \%$ of suicidal ideation. ${ }^{21}$

However, the result of this study was lower than study conducted in Bosnia and Herzegovina, where suicidal ideation was indicated $38 \% .{ }^{17}$ A study of suicide among patients with epilepsy in Havana city of Cuba has shown in $45.2 \%$ of suicidal ideation ${ }^{19}$ whereas in Malaysian study, it was reported $33.75 \%{ }^{40}$ with study result from Brazil indicating $36.7 \%{ }^{41}$ The possible reason for the discrepancy might be the study participants in which the current study used only outpatients, but the study done in Bosnia and Herzegovina and Cuba used both inpatient and outpatients. The other reason might be the sample size where 5013180153 samples were used in Bosnia and Herzegovina, Havana city of Cuba, Malaysia and Brazil, respectively, which were smaller compared with the current study participants $(n=563)$. The difference in study design used might also be another reason for this variation since this study used an institutional based cross-sectional study but a prospective cohort study was used in the Havana city of Cuba, case-control study in Malaysia and communitybased case-control study in Brazil.

On the other hand, the finding of current study was higher than studies done in the USA, which reported a suicidal ideation prevalence ranging from $8 \%$ to $11.9 \%{ }^{37} 42$ and a Canadian study that reported a $12.7 \%$ suicidal ideation. ${ }^{43}$ Similar studies conducted in different countries including Poland, ${ }^{44}$ Rio de Janeiro, Brazil ${ }^{45}$ Republic of china ${ }^{46}$ and Nigeria ${ }^{47}$ reported $10 \%, 13.3 \%$, $14.3 \%$ and $20.0 \%$ suicidal ideation, respectively, which were lower than the current study. The possible reasons for the difference might be variation in study design and the difference in assessment tools used. In the USA, study suicidal ideation was assessed by using the ninth items of beck depression inventory, the same suicidal assessment tool was used in the Poland and Do Rio de Janerio, Brazil studies. The time frame in which the suicidal ideation occurred might be another reason for the difference in the prevalence and many of the previous studies used the current suicidal ideation but the current study considered the lifetime suicidal ideation. The difference in sample size could also be another possible reason for the discrepancy in which the sample sizes ranged from 25 to 251 in the previous studies compared with the 563 participants of the current study.

The magnitude of the suicidal attempt in this study was $12.6 \%$ with (95\% CI 9.9 to 15.5$)$. This study result was in line with study results from Croatia, ${ }^{48} \mathrm{Brazil}^{41} \mathrm{Egypt}^{39}$ and in Addis Ababa Ethiopia ${ }^{24}$ with a reported prevalence of $14.1 \%, 12.1 \%, 11.5 \%$ and $14.1 \%$, respectively.

However, the finding of this study was lower than studies conducted in Havana city of Cuba $28.6 \%,{ }^{19}$ Bosnia and Herzegovina $18 \%^{17}$ and in Brazil 21.2\%. ${ }^{38}$ The possible reasons for the discrepancy might be the difference in study participants. For example, only patients with TLE were the study participants in the Brazil study, whereas both inpatient and outpatients were used in studies conducted in the BosniaHerzegovina and Cuba. The difference in study design could be also another reason. A prospective cohort study was used in Bosnia and Herzegovina, whereas the current was a cross-sectional study.

On other hand, the finding of this study was higher than the study conducted in $\operatorname{Iran}^{13}$ and $\mathrm{Asia}^{21}$ which was $5.5 \%$ and $7.4 \%$ attempted suicide, respectively. This discrepancy might be due to sample size differences where only 200 individuals participated in the Iran study. It was also 
Open access

Table 4 Bivariate and multivariate logistic regression analysis between some selected factors and suicidal ideation among people with epilepsy at enteral Gondar zone primary public hospitals, northwest, Ethiopia, 2020

\begin{tabular}{|c|c|c|c|c|}
\hline \multirow[b]{2}{*}{ Explanatory variables } & \multicolumn{2}{|c|}{ Suicide ideation } & \multirow[b]{2}{*}{ COR $(95 \% \mathrm{Cl})$} & \multirow[b]{2}{*}{ AOR $(95 \% \mathrm{Cl})$} \\
\hline & Yes (N) & No & & \\
\hline \multicolumn{5}{|l|}{ Sex } \\
\hline Male & 70 & 254 & 1 & 1 \\
\hline Female & 79 & 160 & 1.79 (1.23 to 2.61$)$ & $1.68(1.09 \text { to } 3.23)^{*}$ \\
\hline \multicolumn{5}{|l|}{ Marital status } \\
\hline Married & 48 & 235 & 1 & 1 \\
\hline Single & 72 & 136 & 2.59 (1.70 to 3.95$)$ & $1.98(1.70 \text { to } 3.95)^{*}$ \\
\hline Divorced/widowed & 29 & 43 & $3.3(1.87$ to 5.80$)$ & $2.20(1.09 \text { to } 7.8)^{*}$ \\
\hline \multicolumn{5}{|l|}{ Living arrangement } \\
\hline With family & 69 & 290 & 1 & 1 \\
\hline Alone & 80 & 124 & 2.72 (1.85 to 3.98$)$ & 2.40 (1.47 to 3.92$)$ ** \\
\hline \multicolumn{5}{|c|}{ Family history of suicidal attempt } \\
\hline Yes & 35 & 36 & 3.32 (1.99 to 5.55$)$ & $2.53(1.34$ to 4.79$)$ * \\
\hline No & 114 & 379 & 1 & 1 \\
\hline \multicolumn{5}{|c|}{ Family history of committed suicide } \\
\hline Yes & 19 & 22 & 2.6 (1.36 to 4.96$)$ & 1.31 (0.59 to 2.89$)$ \\
\hline No & 130 & 392 & 1 & 1 \\
\hline \multicolumn{5}{|l|}{ Anxiety } \\
\hline Yes & 62 & 58 & 4.25 (2.77 to 6.53$)$ & 2.92 (1.68 to 5.09$)$ ** \\
\hline No & 88 & 356 & 1 & 1 \\
\hline \multicolumn{5}{|l|}{ Depression } \\
\hline Yes & 91 & 77 & 6.87 (4.54 to 10.36$)$ & $3.18(1.85$ to 5.45$) * *$ \\
\hline No & 58 & 337 & 1 & 1 \\
\hline \multicolumn{5}{|l|}{ Ever substance use } \\
\hline Yes & 87 & 144 & 2.63 (1.79 to 3.86$)$ & 1.56 (0.89 to 2.53$)$ \\
\hline No & 130 & 376 & 1 & 1 \\
\hline \multicolumn{5}{|c|}{ Medication for mental illness } \\
\hline Yes & 61 & 27 & 1.75 (1.08 to 2.83$)$ & 1.32 (0.59 to 2.89$)$ \\
\hline No & 62 & 270 & 1 & 1 \\
\hline \multicolumn{5}{|l|}{ Comorbid medical illness } \\
\hline Yes & 22 & 27 & 2.48 (1.37 to 4.51$)$ & $2.60(1.17 \text { to } 5.82)^{*}$ \\
\hline No & 127 & 387 & 1 & 1 \\
\hline Perceived stigma Yes & 84 & 105 & 3.80 (2.57 to 5.63$)$ & 1.50 (0.89 to 2.72$)$ \\
\hline No & 65 & 309 & 1 & 1 \\
\hline \multicolumn{5}{|l|}{ Social support } \\
\hline Poor & 92 & 104 & 3.60 (2.15 to 6.07$)$ & 2.35 (1.26 to 4.40$)$ * \\
\hline Moderate & 32 & 208 & 0.63 (0.35 to 1.16$)$ & 0.49 (0.25 to 1.98$)$ \\
\hline Strong & 25 & 102 & 1 & 1 \\
\hline \multicolumn{5}{|l|}{ Hazardous use } \\
\hline Yes & 33 & 45 & 3.4 (2.08 to 5.57$)$ & 0.51 (0.26 to 1.02$)$ \\
\hline No & 116 & 369 & 1 & 1 \\
\hline
\end{tabular}

$\chi^{2}=10.07, \mathrm{df}=8$, Hosmer-Lemshow test $=0.23$.

${ }^{* *}=p<0.05$, and ${ }^{* *}=p<0.001$.

AOR, adjusted OR; COR, crude OR. 
Table 5 Bivariate and multivariate logistic regression analysis showing an association between factors and suicidal attempt among people with epilepsy at central Gondar zone primary public hospitals, northwest, Ethiopia, 2020

\begin{tabular}{|c|c|c|c|c|}
\hline \multirow[b]{2}{*}{ Explanatory variables } & \multicolumn{2}{|c|}{ Suicidal attempt } & \multirow[b]{2}{*}{ COR $(95 \% \mathrm{Cl})$} & \multirow[b]{2}{*}{ AOR $(95 \% \mathrm{Cl})$} \\
\hline & Yes (N) & No & & \\
\hline \multicolumn{5}{|l|}{ Living arrangement } \\
\hline With family & 30 & 329 & 1 & 1 \\
\hline Alone & 41 & 163 & 2.76 (1.66 to 4.58$)$ & $2.66(1.62 \text { to } 5.41)^{* *}$ \\
\hline \multicolumn{5}{|l|}{ Marital status } \\
\hline Married & 26 & 257 & 1 & 1 \\
\hline Single & 27 & 181 & $1.47(0.83$ to 2.61$)$ & 1.02 (0.52 to 1.99$)$ \\
\hline Divorced/widowed & 18 & 54 & 3.29 (1.69 to 6.43$)$ & $1.92(0.87$ to 4.24$)$ \\
\hline \multicolumn{5}{|c|}{ Family history of committed suicide } \\
\hline Yes & 14 & 27 & 4.23 (2.09 to 8.53$)$ & 2.80 (1.24 to 6.39$)^{*}$ \\
\hline No & 57 & 465 & 1 & 1 \\
\hline \multicolumn{5}{|c|}{ Family history of mental illness } \\
\hline Yes & 12 & 45 & 2.02 (1.01 to 4.04$)$ & 1.62 (0.69 to 3.82$)$ \\
\hline \multicolumn{4}{|l|}{ No } & 1 \\
\hline \multicolumn{5}{|l|}{ Depression } \\
\hline Yes & 50 & 118 & 7.55 (4.35 to 13.08$)$ & $4.87(2.56$ to 9.28$)$ ** \\
\hline No & 21 & 374 & 1 & 1 \\
\hline \multicolumn{5}{|c|}{ Medication for mental illness } \\
\hline Yes & 20 & 68 & 2.45 (1.37 to 4.35$)$ & $2.17(1.06$ to 4.46$){ }^{*}$ \\
\hline No & 51 & 424 & 1 & 1 \\
\hline \multicolumn{5}{|l|}{ Comorbid medical illness } \\
\hline Yes & 38 & 51 & 2.83 (1.42 to 5.66$)$ & 1.71 (0.69 to 4.23$)$ \\
\hline No & 133 & 341 & 1 & 1 \\
\hline $\begin{array}{l}\text { Perceived stigma } \\
\text { Yes }\end{array}$ & 38 & 151 & 2.6 (1.57 to 4.30$)$ & 0.69 (0.51 to 1.84$)$ \\
\hline No & 33 & 341 & 1 & 1 \\
\hline \multicolumn{5}{|l|}{ Hazardous alcohol use } \\
\hline Yes & 23 & 55 & 3.81 (2.15 to 6.73 ) & $2.10(1.05$ to 4.23$)$ * \\
\hline No & 48 & 437 & 1 & 1 \\
\hline
\end{tabular}

${ }^{*} \mathrm{p}<0.05$, and ${ }^{* *}=\mathrm{p}<0.001, \chi^{2}=7.04, \mathrm{df}=8$, Hosmer-Lemshow test $=0.53$. AOR, adjusted OR; COR, crude OR.

lower than a meta-analysis study result $(7.4 \%)$, which was based on pooled prevalence from 18 different studies ${ }^{21}$

Multivariate logistic regression models showed that being woman, living alone, single and divorced/widowed in marital status, depression, anxiety, family history of suicidal attempt, comorbid medical illness and poor social support were significantly associated with suicidal ideation.

In this study, women had about 1.68 times higher suicidal ideation than men. Similar result was reported from studies conducted in the USA ${ }^{42}$ and Poland. ${ }^{44}$ The possible justification for this association might be due to culture influence in which women may not discuss their problems with others as mwn, and it might be due to women having greater vulnerability to other psychosocial stress. The other possible justification might be related to depression in which women are two times more likely to have depression as compared with men. ${ }^{1}$ This is evidenced by a result from meta-analysis study that consists of studies from 30 countries indicating that point prevalence of depression was significantly higher in women. ${ }^{49}$

Participants who lived alone were 2.4 times more likely to have suicidal ideation than those who lived with family. This finding is supported by studies conducted in Washington $^{37}$ and a pervious study done in Addis Ababa Ethiopia. ${ }^{24}$ This might be due to the fact that those who lived alone had no a nearby individual (family) that they could communicate and share their problems and that could lead to increased hopelessness and suicidal ideation. This had also been strengthen by the result regarding marital 
status in which being single and divorced and or widowed were found to be more vulnerable to suicidal ideation though it does not mean these group of participants live alone.This result was supported by a study conducted in Poland. ${ }^{44}$ This might be because of lack of social support and significant other to share emotional and other psychosocial burdens due to various environment stresses that predispose to depression with manifestations including hopelessness and suicidal behaviours.

Regarding to family history of a suicidal attempt, participants who had family history of an attempt were 2.53 times more likely to have suicidal ideation than participants who had no family history of a suicidal attempt. This result was consistent with studies conducted in Croatia, ${ }^{48} \mathrm{Cuba}^{19}$ and previous study in Addis Ababa Ethiopia. ${ }^{24}$ The possible justifications might be from a non-genetic perspective like having a common life style, learnt behaviour, faced with similar family stress and environmental related factors and may also be due to biological predisposition.

Respondents who had depression were 3.18 times more likely to have suicidal ideation than respondents who had no depression. This result was supported by study done in Washington, ${ }^{37}$ Canada, ${ }^{43}$ Bosnia and Herzegovina, ${ }^{17}$ Poland, ${ }^{44}$ Brazil,${ }^{38}$ Malaysia, ${ }^{40}$ Korea, ${ }^{36}$ Nigeria $^{47}$ and Addis Ababa Ethiopia. ${ }^{24}$ Many of this previous studies justified that the presence of depression is highly associated with suicidal ideation. The possible reason might be due to the direct effect of depression, which makes individuals feel hopeless and worthless. It also indicated that the decreased level of serotonin neurotransmitter in the brain of a depressed individual was found to be associated with increased suicidal behaviour. ${ }^{50}$

Regarding anxiety, participants who had anxiety were 2.9 times higher likely to have suicidal ideation than participants who had no anxiety. This was similar with the study done in Canada, ${ }^{43}$ Brazil $^{41}$ Korea $^{36}$ and Nigeria. ${ }^{47}$ The possible reason for this may be fear of adapting to and anxious feeling about the illness and drug, fear of a seizure attack, increasing psychological stress and pressure related to epilepsy.

Another factor that was associated with suicidal ideation was poor social support. Respondents with poor social support were 2.35 times higher likely to have suicidal ideation as compared with strong social support. It was similar with other studies done in Havana city of Cuba, ${ }^{19}$ China ${ }^{46}$ and Addis Ababa Ethiopia. ${ }^{24}$ The WHO report revealed that weak social ties and low support from relatives have been significantly associated with suicidal ideation. $^{51}$

With respect to a suicidal attempt, respondents who had depression were 4.87 times more likely to have a suicidal attempt than those who had no depression. This is consistent with study conducted in Canada, ${ }^{43}$ Washington, ${ }^{37}$ Poland, ${ }^{44}$ Brazil,${ }^{38}$ Malaysia, ${ }^{40}$ Korea, ${ }^{36}$ Nigeria $^{47}$ and Addis Ababa Ethiopia. ${ }^{24}$ The possible justification for this might be that depression will decrease the neurotransmitter serotonin, as studies have shown an association between decreased level of serotonin and its metabolite and being suicidal. ${ }^{50}$ On the other hand, depression can be a direct effect on the feeling of hopeless and worthless.

Those study respondents who were taking medication for mental illness in addition to antiepileptic medication were highly risk for suicidal attempt. This was similar to study conducted in Washington, ${ }^{37}$ Croatia, ${ }^{48}$ Korea ${ }^{36}$ and Addis Ababa Ethiopia. ${ }^{24}$ Having two chronic illnesses and pill burden to treat the illnesses took longer time to recover and make negative feeling, which could lead feeling hopeless and worthless and finally suicidal attempts.

Those study participants who had a family history of committed suicide were 2.8 times more likely to have a suicidal attempt as compared with those who had no family history of a committed suicide. The result is supported by the previous study done in Addis Ababa Ethiopia. ${ }^{24}$ The possible reason might be due to biological perspective and might be due to non-biological factors like sharing similar family stress and environmental factors.

Regarding alcohol use, participants who had hazardous alcohol use were 2.1 times higher to a suicidal attempt as compared with those who had no hazardous alcohol use, this was supported by a study conducted in Croatia. ${ }^{48}$ This might be due to participants who drink alcohol were exposed to increased impulsiveness, poor judgement and a weakening of normal restraints against dangerous behaviour. And they might also consider suicidal ideation in withdrawal state due to dysphonic feeling related with alcohol withdrawal.

\section{Limitation of study}

The use of retrospective items in the questionnaire may have incurred recall bias like duration of illness and duration of treatment. The cross-sectional nature of the study was its main limitation. In addition, the ever suicidal ideation and attempt were used to do the analysis as there were very few responses for the current suicidal ideation and attempt. This could be another limitation as it was difficult to determine the temporal relation between suicidal ideation and attempt and associated factors. It is difficult to address types of epilepsy since it was difficult to get specific diagnosis from the patient chart. Though there are evidences from previous study results that indicated the role of personality disorders in suicide, the current study did not assess personality disorders among patients with epilepsy. ${ }^{52}$

\section{CONCLUSION}

This study showed that suicidal ideation and attempt were common among people with epilepsy. Being woman, living alone, single, divorced/widowed in marital status, family history of suicidal attempt, anxiety, depression, comorbid medical illness and poor social support were significantly associated with suicidal ideation. Family history of committing suicide, living alone, depression, taking medication for mental illness and hazardous 
alcohol use were significantly associated with suicidal attempt. Therefore, it is better to give due emphasis and screen patients with epilepsy to suicidal ideation and ask history of suicide attempt including depression and anxiety as routine clinical evaluation. Providing intervention targeting risk factors to these groups of people is also vital.

Acknowledgements The authors acknowledge the University of Gondar for facilitating the study. We extend our gratitude to data collectors, supervisors and study participants for their time and effort in data collection and information provision.

Contributors KN designed the study, involved in the data collection, analysis and write up. HK and BT involved in design, data analysis and drafted the manuscript. AL participated in the analysis of the data and critically reviewed the manuscript. All authors read and approved the final manuscript.

Funding The authors have not declared a specific grant for this research from any funding agency in the public, commercial or not-for-profit sectors.

Competing interests None declared.

Patient and public involvement Patients and/or the public were not involved in the design, or conduct, or reporting, or dissemination plans of this research.

Patient consent for publication Not required.

Provenance and peer review Not commissioned; externally peer reviewed.

Data availability statement Data are available upon reasonable request. All data relevant to the study are included in the article or uploaded as supplementary information. Data are available upon reasonable request to the corresponding author.Email: habtaishk@gmail.com

Open access This is an open access article distributed in accordance with the Creative Commons Attribution Non Commercial (CC BY-NC 4.0) license, which permits others to distribute, remix, adapt, build upon this work non-commercially, and license their derivative works on different terms, provided the original work is properly cited, appropriate credit is given, any changes made indicated, and the use is non-commercial. See: http://creativecommons.org/licenses/by-nc/4.0/.

\section{ORCID iD}

Habtamu Kerebih http://orcid.org/0000-0002-0656-7716

\section{REFERENCES}

1 Sadock BJ, Sadock VA. Kaplan and Sadock's synopsis of psychiatry: Behavioral sciences/clinical psychiatry. Lippincott Williams \& Wilkins, 2011.

2 Mann JJ, Apter A, Bertolote J. Suicide prevention strategies: a systematic review. Jama 2005;294:2064-74.

3 Association AP. Diagnostic and statistical manual of mental disorders (DSM-5®). American Psychiatric Pub, 2013.

4 Rudd MD. Suicide warning signs in clinical practice. Curr Psychiatry Rep 2008;10:87-90.

5 Beautrais AL, Mishara BL. World Suicide Prevention Day:"think globally, plan nationally, act locally". Hogrefe \& Huber Publishers, 2008.

6 Organization WH. Preventing suicide: a global imperative. World Health Organization, 2014.

7 Czerwik-Kulpa M, Chylińska J. Quality of life in palliative care. Acta Neuropsychologica 2010;8:244-62.

8 Organization WH. Neurological disorders: public health challenges. World Health Organization, 2006.

9 Organization WH. WHO-AIMS: mental health systems in selected low-and middle-income countries: a WHO-AIMS cross-national analysis. World Health Organization, 2010.

10 Organization WH. Initiative of support to people with epilepsy. Geneva: World Health Organization, 1990.

11 Tekle-Haimanot R, Abebe M, Gebre-Mariam A, et al. CommunityBased study of neurological disorders in rural central Ethiopia. Neuroepidemiology 1990;9:263-77.

12 Alsaadi T, Zamel K, Sameer A, et al. Depressive disorders in patients with epilepsy: why should neurologists care? Health 2013;05:14-20.

13 Kasmaei HD, Hesami O, Jabbehdari S. Prevalence of suicidal ideation and attempts in patients with epilepsy. Thrita 2015;4.
14 Christensen J, Vestergaard M, Mortensen PB, et al. Epilepsy and risk of suicide: a population-based case-control study. Lancet Neurol 2007;6:693-8.

15 Karouni M, Arulthas S, Larsson PG, et al. Psychiatric comorbidity in patients with epilepsy: a population-based study. Eur J Clin Pharmacol 2010;66:1151-60.

16 Pack AM. Epilepsy and suicidality: what's the relationship? Epilepsy Curr 2016;16:236-8.

17 Loga Andrijić N, Alajbegović A, Loga Zec S. Suicidal ideation and thoughts of death in epilepsy patients. Psychiatria Danubina 2014;26:0-55.

18 Jones JE, Hermann BP, Barry JJ, et al. Rates and risk factors for suicide, suicidal ideation, and suicide attempts in chronic epilepsy. Epilepsy \& Behavior 2003;4:31-8.

19 Machado RA, Espinosa AG, Melendrez D, et al. Suicidal risk and suicide attempts in people treated with antiepileptic drugs for epilepsy. Seizure 2011;20:280-4.

20 Kanner AM. Suicidality and epilepsy: a complex relationship that remains misunderstood and underestimated. Epilepsy Curr 2009;9:63-6.

21 Abraham N, Buvanaswari P, Rathakrishnan R, et al. A meta-analysis of the rates of suicide ideation, attempts and deaths in people with epilepsy. Int J Environ Res Public Health 2019;16:1451.

22 Jones JE, Bordenave JM. Suicide in children and adults with epilepsy: a complex relationship. Suicide Prevention: Springer, 2018: 119-42.

23 Staniszewska A, Dąbrowska-Bender M, Sobiecki M. Epidemiology and risk factors for suicide among adult patients with epilepsy. EPILEPTOLOGY 2016;131.

24 Haile K, Awoke T, Ayano G, et al. Suicide ideation and attempts among people with epilepsy in Addis Ababa, Ethiopia. Ann Gen Psychiatry 2018;17:4.

25 Fazel S, Wolf A, Långström N, et al. Premature mortality in epilepsy and the role of psychiatric comorbidity: a total population study. The Lancet 2013;382:1646-54.

26 Scott KM, Hwang I, Chiu W-T, et al. Chronic physical conditions and their association with first onset of suicidal behavior in the world mental health surveys. Psychosom Med 2010;72:712-9.

27 Meyer N, Voysey M, Holmes J, et al. Self-Harm in people with epilepsy: a retrospective cohort study. Epilepsia 2014;55:1355-65.

28 Nilsson L, Ahlbom A, Farahmand BY, et al. Risk Factors for Suicide in Epilepsy: A Case Control Study. Epilepsia 2002;43:644-51.

29 Kessler RC, Üstün TB. The world mental health (WMH) survey initiative version of the world Health organization (who) composite international diagnostic interview (CIDI). Int J Methods Psychiatr Res 2004;13:93-121.

30 Gelaye B, Williams MA, Lemma S, et al. Diagnostic validity of the composite international diagnostic interview (CIDI) depression module in an East African population. Int $J$ Psychiatry Med 2013;46:387-405.

31 Hodgson R, Alwyn T, John B. The fast alcohol screening test. Alcohol and Alcoholism 2002;37:61-6.

32 Shibre T, Hanlon C, Medhin G, et al. Suicide and suicide attempts in people with severe mental disorders in Butajira, Ethiopia: 10 year follow-up of a population-based cohort. BMC Psychiatry 2014;14:1-12.

33 Reda AA. Reliability and validity of the Ethiopian version of the hospital anxiety and depression scale (HADS) in HIV infected patients. PLoS One 2011;6:e16049.

34 Dalgard OS, Dowrick C, Lehtinen V, et al. Negative life events, social support and gender difference in depression. Soc Psychiatry Psychiatr Epidemiol 2006;41:444-51.

35 Mbuba CK, Abubakar A, Odermatt P, et al. Development and validation of the Kilifi stigma scale for epilepsy in Kenya. Epilepsy \& Behavior 2012;24:81-5.

$36 \mathrm{Lim} \mathrm{H-W}$, Song H-S, Hwang Y-H, et al. Predictors of suicidal ideation in people with epilepsy living in Korea. J Clin Neurol 2010;6:81-8.

37 Hecimovic H, Santos JM, Carter J, et al. Depression but not seizure factors or quality of life predicts suicidality in epilepsy. Epilepsy \& Behavior 2012;24:426-9.

38 de Oliveira GNM, Kummer A, Salgado JV, et al. Suicidality in temporal lobe epilepsy: measuring the weight of impulsivity and depression. Epilepsy Behav 2011;22:745-9.

39 Hamed SA, Elserogy YB, Abdou MA, et al. Risks of suicidality in adult patients with epilepsy. World J Psychiatry 2012;2:33.

40 Rani RA, Razali R, Hod R. Suicidal ideation amongst epilepsy patients in a tertiary centre. Neurology Asia 2014;19.

41 Stefanello S, Marín-Léon L, Fernandes PT, et al. Psychiatric comorbidity and suicidal behavior in epilepsy: a community-based case-control study. Epilepsia 2010;51:1120-5. 
42 Husari KS, Blackburn KM, Ding K, et al. Assessing recent suicidal ideation and behavior in the adult epilepsy monitoring unit. Epilepsy \& Behavior 2019;94:100-3.

43 Altura KC, Patten SB, Fiest KM, et al. Suicidal ideation in persons with neurological conditions: prevalence, associations and validation of the PHQ-9 for suicidal ideation. Gen Hosp Psychiatry 2016;42:22-6.

44 Bosak M, Turaj W, Dudek D, et al. Suicidality and its determinants among Polish patients with epilepsy. Neurol Neurochir Pol 2016;50:432-8.

45 Wigg CMD, Filgueiras A, Gomes MdaM. The relationship between sleep quality, depression, and anxiety in patients with epilepsy and suicidal ideation. Arq Neuropsiquiatr 2014;72:344-8.

46 Ding S, Li X, Hua Y, et al. Risk factors for suicidal tendency in adult patients with epilepsy in China. Epilepsy \& Behavior 2019;97:118-22.
47 Nuhu FT, Lasisi MD, Yusuf AJ, et al. Suicide risk among adults with epilepsy in Kaduna, Nigeria. Gen Hosp Psychiatry 2013;35:517-20.

48 Buljan R, antić AM. Suicide attempts in hospital-treated epilepsy patients. Acta Clinica Croatica 2011;50:485-9.

49 Lim GY, Tam WW, Lu Y, et al. Prevalence of depression in the community from 30 countries between 1994 and 2014. Sci Rep 2018;8:1-10.

50 Courtet P, Baud P, Abbar M, et al. Association between violent suicidal behavior and the low activity allele of the serotonin transporter gene. Mol Psychiatry 2001;6:338-41.

51 Bertolote JM, Fleischmann A, De Leo D, et al. Psychiatric diagnoses and suicide: revisiting the evidence. Crisis 2004;25:147-55

52 Choo C, Diederich J, Song I, et al. Cluster analysis reveals risk factors for repeated suicide attempts in a multi-ethnic Asian population. Asian J Psychiatr 2014;8:38-42. 